\title{
The Investigation and Analysis of the New Generation Farmers' Information Literacy in Chongqing Province
}

\author{
Xiaoyan Zhong $^{1}, K_{\text {KunQu }}{ }^{1}$
}

${ }^{1}$ School of computer and information science, Southwest University, Chongqing, China

\begin{abstract}
In the process of agriculture informatization, how to effectively promote the famers' information literacy is crucial to solving three dimensional rural issues. On the basis of questionnaire and interviewing methods, this thesis analyzes and discusses the new generation farmers' information literacy in Chongqing province, and it is expected to be helpful for the similar researches.
\end{abstract}

Key words: Chongqing province; the new generation; famer; information literacy

Supported by "The Fundamental Research Funds for the Central

Universities: Theoretical Research and Practices of Integrating and Sharing (Rural) Agricultural Information Resources in Chongqing". ( Project Number:XDJK2013C082)

\section{Introduction}

Starting from 2004, the Chinese government introduced measures of benefiting and strengthening which related to the issues of agriculture, farmer and rural area in the form of No.1 document of government. During the 12th Five-Year Plan, the government underlined to advance the agricultural modernization, and accelerate the construction of new socialist countryside. It is well known that informatization is an irreversible major tendency in today's world economic and social development, and it is also a revolution of technology, industry, and society after the industrialization. Agriculture informatization has become the inevitable way to promote agricultural modernization. In addition to the infrastructure construction, agriculture informatization depends on the training of qualified personnel of agricultural informatization, especially the raising of new farmers generation's information 
literacy. For this purpose, the research and analysis of the present situation of the new farmer generation's information literacy and their enhancing approaches has important role and realistic significance for realizing the agriculture informatization and modernization.

\section{The definition of the "new farmer generation" and their information literacy}

On January 31st, 2010, the formulation of "New Farmer Generation" first appeared in the No.1 Document about increasing the intensity of balancing and coordinating the urban and rural development and further consolidating agricultural rural development foundation. Later on, although there were many scholars in academic field interpreted this concept, they do not reach consensus so far. In this article the author considers that the New Farmers Generation are mainly young farmers who was born in 1980s and 1990s, and the age ranges from 18 to 30.

The concept of information literacy was put forward 1n 1974 by Paul G. Zurkowski, the president of AIIL. According to Paul's idea, the information literacy contains information awareness, information knowledge, information ability, and information ethics. There are different standards in different times and areas while analyzing people's information literacy. In this article, the author considers the New Farmers Generation's information literacy covers the same aspects above. Specifically as follows:

\subsection{Information Awareness}

Information awareness refers to people's sum of cognition, concept, and demand. The New Farmers Generation's information awareness is characterized by farmers' sensibility and insight toward information. To be specific, information awareness mainly means that if the New Farmer Generation will take the initiative to comprehend information through newspaper, television, and Internet from the perspective of their production and living with a certain anticipating information consciousness.

\subsection{Information Knowledge}

Information Knowledge refers to the prerequisite relevant knowledge involved in information activities. The prerequisite relevant knowledge includes five aspects: literacy, such as reading, writing, and mathematics; communication, transmission, and management of knowledge; operation of the information technology; information laws and ethical knowledge; the basic language proficiency. 


\subsection{Information Ability}

Information ability defines from the level of technical operation, and it refers primarily to the New Farmers Generation's ability of collecting, identifying, managing, and exchanging information. Information ability includes the information collection and query capabilities, the information identification ability, the application ability, and communication transmission capacity.

\subsection{Information ethics}

Information ethics refers that the New Farmers Generation should respect others, and comply with laws and regulations.

\section{The investigation and analysis of information literacy of new farmer generation in Chongqing Province}

\subsection{The investigation}

\subsubsection{Purpose and content}

The investigation was carried out in the forms of questionnaire and interview to get a relatively comprehensive understanding of information literacy of new farmer generation in Chongqing Province. The content of this investigation include information awareness (such as, the willingness to know about and obtain information, and the sensitivity towards information), information knowledge and competence (such as, the familiarity towards traditional information tools and modern information facilities, and the ability to collect, utilize and differentiate information), and information ethics.

\subsubsection{Participants}

Chongqing Province is located in Southwest China. It is a typical mountainous and hilly area, inland city, as well as agricultural metropolis. The rural area covers $95 \%$ of the total area, with a rural population of approximately 22 million, which accounts for $66 \%$ of the total population in Chongqing Province. There are 38 districts and counties in Chongqing Province. The investigation selected 18 counties which are key areas of in-process poverty relief and development, and another 15 that are in the Three Gorges Reservoir Region. 50 households of farmers, who were born after 1980 and live mainly on engaging in agricultural production, were randomly selected from each district and county.

1850 questionnaires were handed out in this survey and 1792 were retrieved, among which 1550 were valid, accounting for $83.8 \%$ in total. 


\subsection{Results and analysis}

\subsubsection{Educational background investigation}

According to the results, among all the participants in this survey, 5.5\% received elementary education; $68.5 \%$ received middle school education; $18 \%$ received secondary education; only $4.8 \%$ of them received vocational secondary education; farmers that obtained tertiary education or further only accounts for 3.2\%. All participants received education on the whole. The new farmer generation in this survey has received China's compulsory education. However, more than half of them do not have averagely enough education.

\subsubsection{Survey on information awareness}

\subsubsection{The awareness of the importance of information}

In the survey, $75.3 \%$ of the new farmer generation holds the belief that information is of crucial importance to promoting agricultural production as well as farmers' living standards. $22.4 \%$ of them think that information is of average importance. Another $2.3 \%$ of new farmer generation is not aware of the importance of information. They believe that information has nothing to do with their product and life. As shown in Figure 1.

\subsubsection{The awareness of solving problems with information technology}

When asked in what ways they solve the problems in production and daily life, $17.3 \%$ of new farmer generation choose to read related books. $33.6 \%$ of them choose to search resources from internet, while the rest of them mostly depend on consulting others to solve problems. As shown in Figure 2.

चery important $\square$ important $\square$ Idon't care

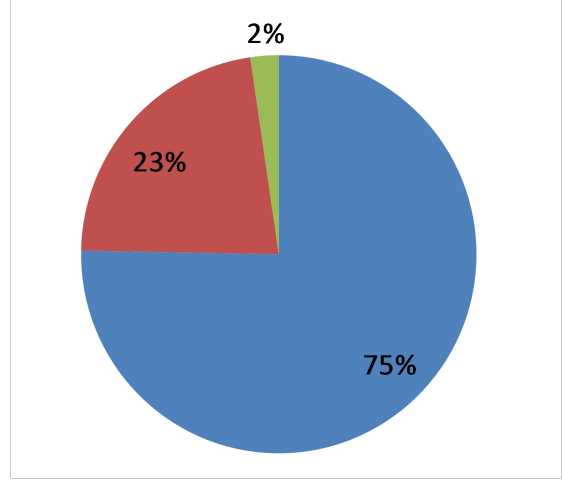

Fig.1. the awareness of the importance of information

घooks $\square$ online resources $\square$ consulting other

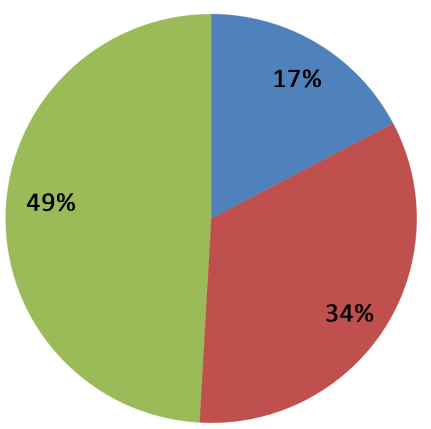

Fig.2. The awareness of solving problems with information technology 


\begin{tabular}{|l|c|c|c|c|}
\hline \multicolumn{1}{|c|}{ Research Content } & $\begin{array}{c}\text { Expertized } \\
\text { (per person) }\end{array}$ & $\begin{array}{c}\text { Skilled (per } \\
\text { person) }\end{array}$ & $\begin{array}{c}\text { Less Skilled } \\
\text { (per person) }\end{array}$ & $\begin{array}{c}\text { Incapable } \\
\text { (per person) }\end{array}$ \\
\hline Searching the resources need through the Internet & 2 & 133 & 1233 \\
\hline Applying search engines such as Google and Baidu & 2 & 52 & 1230 & 266 \\
\hline Applying communication tools such as QQ and Email & 78 & 667 & 1027 & 337 \\
\hline $\begin{array}{l}\text { Applying anti-virus software such as 360 Security } \\
\text { Guards and Kingsoft Internet Security }\end{array}$ & 2 & 184 & 1353 & 168 \\
\hline Applying Microsoft Office such as Word and Excel & 2 & 27 & 2673 \\
\hline
\end{tabular}

According to the analysis above, the new generation of farmers is able to realize the important influence that information has on agricultural production and farmers' lives. However, the awareness of solving problems with information technology is yet to be more thoroughly spread.

c. Survey on information knowledge and ability

The knowledge of information and the ability to use information are two inseparable contents in this survey. The knowledge shows potential ability and the ability suggest the familiarity of the knowledge. The study focuses mainly on the new farm generation's basic operation on computer as well as internet in this survey and the follow-up analysis.

Nowadays, the application of computers and internet communication technology has become a must in all walks of life. However, it is impossible to have every person professional in commuter and internet operation, especially new farmer generation. According to the investigation, the author also finds that $11.7 \%$ of new farmer generation does not know how to collect resource from internet. As the most widespread search engines, Google and Baidu are beyond the knowledge of $17.2 \%$ of new farmer generation. Nonetheless, nearly half of them are able to use communication tools, such as QQ and E-mail. They think that communication go faster and more smooth in this way with relatively lower cost than other kinds of communication manners. More than half of farmers in this survey can utilize antivirus program, which is considered indispensible for computers, with a minority of $21.7 \%$ unaware of the usage of those antivirus software. In addition, office software such as Word and Excel could be operated by the majority of the participants, but with less familiarity. 


\subsubsection{Survey on information ethics}

Information ethics is of crucial function in order to build a well-functioning information environment. Therefore, the author carried out a simple survey on information ethics among participants.

\subsubsection{Attitudes towards fake information}

The results of this survey suggest that more than half of the participants choose to ignore when they receive fraud text messages. $47.8 \%$ of them will even warn their families and friends not to believe in such messages. $1.7 \%$ of them choose to report to the office or relevant departments so that the fraud messages could be somehow stopped. As shown in Figure 3.

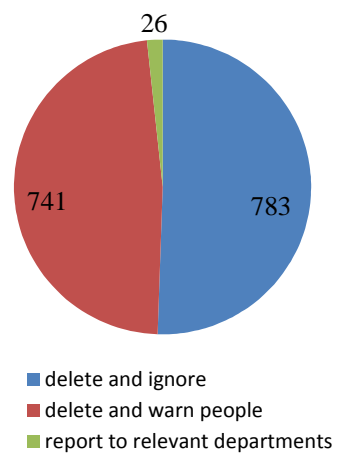

Fig 3. Attitudes towards fake information

\subsubsection{Attitudes towards unwholesome information}

When it comes to the inappropriate information online, the majority of participants hold a strong sense of hatred. Only $6.6 \%$ of them have unintentionally browsed similar webpage. $93.4 \%$ of them express that they have never found or browsed unwholesome information. As shown in Figure 4.

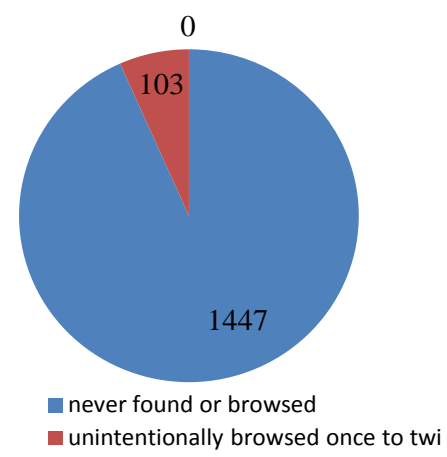

Fig 4. Attitudes towards unwholesome information

\section{The results of the investigations and analysis of information literacy of new farmer generation in}

Chongqing Province

According to the investigation and analysis of related data of information literacy of new farmer generation in Chongqing Province, the author find several problems in the process of promoting informatization in rural areas in Chongqing Province, especially problems existing in information literacy among new generation of farmers. To summer up, there are several aspects to address these issues as follows: 


\subsection{The overall information literacy of new farmer generation is unpleasant}

First of all, the awareness of information literacy of new farmer generation in Chongqing Province is relatively weak that lacks sensitivity and initiative. Although they are able to be aware of the important function of information in modern agricultural production and life, they are not clear with what kind of information they need or how to make the best of information when they get access to information.

Secondly, the new farmer generation does not have a good knowledge about information, especially computer technology, not to mention the operation of internet as well as problems that are caused along the process. With computer and internet being one of the most important tools of collecting information, the fact that the new farmer generation has little knowledge about information technology put agricultural production and life as a disadvantageous situation.

Thirdly, although the new generation of farmers' information competence cannot be determined by several indexes, the ability to utilize modern information tools has become one of the most important indexes to determine people's information literacy. Due to lack of information knowledge, new farmer generation shows lower ability in terms of the mastering and utilizing of modern information tools.

Last but not least, according to this survey, the majority of new generation farmers are able to deal with fraud and unwholesome information in a correct way. Meanwhile, $1.7 \%$ of them take measures to fight against fake information, suggesting the social responsibility that is shared among them. However, this is only the case with the minority of the participants. The information ethics of the majority of new farmer generation is yet to be improved.

\subsection{Information education of new \\ farmer generation does not meet the demand of time.}

Further analyses of the in-depth reasons of relatively low information literacy reveal the limitations of basic education among new farmer generation. Education decides a person's ability and quality to a great extent. In this investigation, more than $70 \%$ of participants have only received the most basic compulsory education. Information technology education could not be fulfilled because there is a lack of teachers and facilities in rural areas in Chongqing Province, especially those extremely poor rural areas. Through interviewing participants, the author also finds that the majority of new farmer generation has never received any 
education on information technology. All those factors contribute to the fact that the overall information literacy of new farmer generation is unpleasant. Therefore, in the process of promoting informatization in rural areas, farmers' information literacy education should also be put into consideration.

\subsection{The relatively lagging rural information service in Chongqing Province}

From the perspective of the rural information service projects, the rural network construction in Chongqing remains to be further strengthened. Though the major network operators have built the corresponding infrastructure, the popularity of network is not enough. If people still rely on traditional medium to acquire information to a greater degree, such as books and television, it will go against farmers'knowledge and the competence of utilizing.

From the perspective of the rural information service contents, there is a lack of correct information guide and more comprehensive information service for new generation farmers. Information service is not just to provide information hardware facility, what is more important is that they should learn how to obtain and employ required information. According to the current situation, the information service contents in rural area are still in its beginning stage.

From the perspective of the rural information service, most new farmer generation in the interview part suggest that it cost less to install broadband at home than before. However, compared with other household expenses, that fee is still considered a little too much. They also express their expectation of more economical and affordable information service with nothing else changes.

The improvement of farmers' information literacy is of profound significance and importance as to increase their incomes, renew their viewpoint, and improve their living standards. Therefore, it is imperative to take relevant measures to promote new farmer generation's information literacy from multiple channels, in different angles to its full potential.

\section{References}

[1] Xuejun Wang, Tinan Lei. Strategy Research about Improving Famers' Information Literacy Based on the Modern Distance Education Project of Middle and Primary Schools in Western Rural Area. Software Journal [J], 2009(6):24-26

[2]Wanjun Ge. Research on Improving Famers' Information Literacy. Modern Agricultural Science and Technology [J], 2009(22):398 